\title{
EDITORIAL
}

\section{International Psychogeriatrics 2019: the year in review}

The International Psychogeriatrics (IPG) is the flagship journal of the International Psychogeriatric Association (IPA). The IPA was founded in 1982. Today its membership includes physicians (psychiatrists, neurologists, geriatricians, primary care clinicians, among others), psychologists, nurses, social workers, occupational therapists, researchers, epidemiologists, and many others. With members from more than 50 countries, the IPA brings together psychogeriatricians from various backgrounds. The IPG was born in 1989 (Cohen et al., 1989). I feel fortunate to have been chosen to follow in the footsteps of several outstanding Editors-in-Chief (Lautenschlager 2014). The first issue of the new Editorial Board was published in January 2018 (Jeste, 2018a). I am proud to say that the journal has made considerable progress during the past year, thanks to the incredibly collaborative work involving IPG Editorial Board, IPA leadership, Cambridge Press, authors, reviewers, and readers. Below is a summary of our progress as well as plans for the coming year.

The IPG reflects the global vision and mission of the IPA in being a multidisciplinary, peer-reviewed journal for researchers, clinicians, and educators in geriatric psychiatry, with a broad encompassing approach to aging, including mental and cognitive health and illnesses and taking into account biological as well as psychosocial perspectives.

The new Editorial Board includes about 30 Triage Editors from a number of countries and covering various professions. We have four Deputy Editors: Steve Arndt, PhD; Henry Brodaty, MD; Gill Livingston, $\mathrm{PhD}$; and Kostas Lyketsos, MD. The Board members include several junior colleagues - fellows or junior faculty who, with mentorship and experience, will become the future leaders of our field. We count on invaluable input from numerous reviewers. Every submitted paper is reviewed by me as the Editor-in-Chief or one of the Deputy Editors. We decide if the paper is clearly suited for the IPG and whether it is of sufficiently high quality. If a paper does not meet both of these criteria, it is rejected without further external review, so the authors can quickly submit it to another journal. The small number of papers that pass the initial filter are sent out for external reviews. We typically select two reviewers for each paper, almost always including a statistical reviewer for data-based papers. Without the reviewers' generous help, the peer-review process would not be possible.

Running a journal is a team work. The Board of Directors of the IPA, led by the IPA President (Bill Reichman, MD), plays a major role in shaping and supporting the mission of the IPG, while scrupulously avoiding even an appearance of unnecessary influence on editorial independence. Important members of the IPG team also include the staff of the Cambridge University Press, publishers of the journal, specifically Jessica Bradley, the Publishing Editor; Elaine Halls, the IPG Editorial Office Manager; Kayla Riddleberger, the Associate Production Editor; and Joon Won Moon, the Marketing Manager.

\section{Submissions, decisions, and turnaround times}

The IPG has continued to grow rapidly. The number of manuscripts received has maintained an upward trend over the past several years and is on the way to reach a new high of 500 this year - a major milestone for our journal. The submitted articles come from various countries across the globe. Table 1 provides the numbers of articles in various categories received during the last 5 years. The largest category of unsolicited articles is that of original research articles, followed by review papers. We no longer publish case reports or protocol-only papers.

To keep up with the increasing numbers of submissions and increase the quality of published papers, the acceptance rates of the submitted manuscripts have been reduced significantly. Figure 1 depicts the changing rates of acceptance of the articles during the last 5 years. This year the rate of acceptance of unsolicited articles (i.e. excluding Invited Commentaries and Guest Editorials) will be below $30 \%$ for the first time, and it is expected to decline further during the coming year.

The authors of submitted new papers expect early decisions so that the accepted papers would be published and the rejected papers can be resubmitted to another journal more quickly. Therefore, we have markedly shortened our turnaround times. An important priority for us is to reduce the time for the first as well as the final decisions. As shown in 
Table 1. Original manuscripts received by article type, 2015-2019

\begin{tabular}{lccccc}
\hline & 2015 & 2016 & 2017 & 2018 & 2019 Projections \\
Brief Reports & 0 & 18 & 0 & 30 & 32 \\
Case Reports & 16 & 16 & 12 & 0 & 0 \\
Invited Commentaries & 10 & 12 & 10 & 13 & 50 \\
Editorials/Guest Editorials & 9 & 17 & 11 & 2 & 7 \\
Letters to the Editor & 17 & 11 & 15 & 16 & 23 \\
Original Research Articles & 333 & 323 & 335 & 341 & 350 \\
Protocol-Only Articles & 0 & 4 & 3 & 4 & 0 \\
Review Articles & 39 & 41 & 60 & 34 & 49 \\
Total Articles Received & 424 & 442 & 471 & 440 & 511 \\
\hline
\end{tabular}

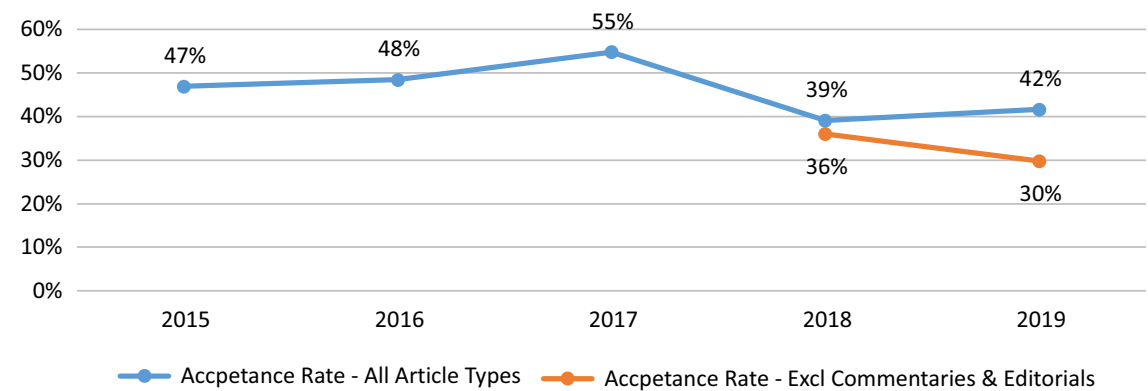

Figure 1. Acceptance Rates, 2015-2019.

*2018 \& 2019 figures in orange color reflect all articles types excluding Invited Commentaries and Editorials.

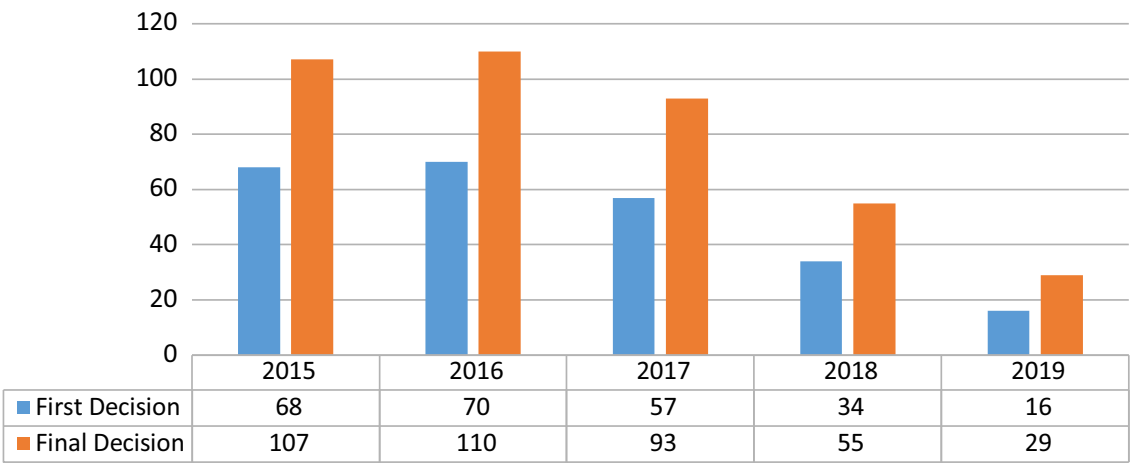

Figure 2. Average Turnaround Times (Days), 2015-2019.

Figure 2, the mean time to first decision is now 16 days, while that to the final decision is 29 days. These are among the shortest average times to decisions among peer-reviewed journals in our field. Sometimes, unfortunately, there are delays in reviews of individual papers because of difficulties in finding reviewers who are experts in the specific area, have no conflicts of interest, and are willing to review. This is a problem that practically all the medical journals are currently facing. The IPA has recently initiated a program to offer continuing education credits to reviewers whose reviews are both timely and of high quality.

\section{Monthly issue themes}

One of my initiatives focuses on developing themefocused issues of the IPG. The goal is to have several (but only a limited number of) papers on a common theme. After choosing a theme, I invite outside experts to write a Commentary on the respective article/s to highlight their strengths as well as limitations and to suggest directions for advancing research or clinical care in that particular area of work. Such theme-focused issues are highly valued not only by researchers but also by trainees and clinicians. I should add that, to ensure balance of topics, 
Table 2. List of themes for monthly issues, 2019 (Volume 31)

\begin{tabular}{|c|c|c|}
\hline Month & Issue & Theme \\
\hline January & 1 & Parkinson's Disease \\
\hline February & 2 & Positive Psychiatry \\
\hline March & 3 & Caregiving for People with Dementia \\
\hline April & 4 & Aging and Well-Being \\
\hline May & 5 & Well-Being in Dementia \\
\hline June & 6 & Frailty, Cognition, and Mental Health \\
\hline July & 7 & Diverse Approaches to Stemming Cognitive Decline \\
\hline August & 8 & Dementia Care \\
\hline September & 9 & Self-Esteem, Resilience, and Emotional Intelligence \\
\hline October & 10 & Dementia and the Society \\
\hline November & 11 & Psychiatric Morbidity in Exceptionally Old People \\
\hline December & 12 & Assessment of Neuropsychological Impairment in East Asia \\
\hline
\end{tabular}

a majority of the articles published in an issue are not on the selected theme. Furthermore, we also attend to diverse themes within our field. While dementias and other neuropsychiatric disorders of late life continue to be a critical arena of clinical care, research, and education, we must also pay attention to successful cognitive and emotional aging. The themes of the issues of the IPG published from January through December of 2019 are listed in Table 2. These themes have included disorders including dementias and Parkinson's Disease as well as positive aspects of mental health and aging such as well-being, self-esteem, and emotional intelligence. Psychiatry should not be restricted to studying and treating mental illnesses only. While treating psychiatric disorders will always be our primary responsibility, we also need to study and promote mental health, well-being, and positive psychosocial factors like resilience, optimism, wisdom, and social support - this constitutes the Positive Psychiatry of Aging (Jeste, 2018b).

\section{Measures of impact}

How does one measure the success of a peerreviewed journal? While growing numbers of submissions clearly point to increasing popularity of the journal among researchers, there are other equally meaningful measures too. For me, the IPA members' opinion about the value of their journal is critical. I am delighted to report that, in a recent survey of membership, the IPG was rated as one of the most important benefits of belonging to the IPA. There are also additional ways of evaluating a journal's usefulness to all of its readers. These include usage statistics, Impact Factor, and Altmetric score.

Usage statistics refer to online abstract view counts, full-text (pdf or HTML) view counts, and homepage view counts. These data are recorded daily for the Journal. Table 3 includes the 20 most popular articles published in the IPG during the last year in terms of usage statistics.

From the research perspective, peer-reviewed journals have been traditionally judged by the frequency with which the papers published are cited by various authors. The specific measure for this purpose is called the Impact Factor, which is calculated by the number of citations made in any given year to papers published in the journal within the 2 consecutive years immediately preceding, divided by the total number of eligible articles published during those 2 years. Thus, the 2018 Impact Factor for the IPG is computed as follows: Number of cites to IPG papers during 2018 to items published in 2017 and 2016 (=917) divided by the Number of papers published in: 2017 and $2016(=370)$. The resulting number is 2.478 - that is the Impact Factor for IPG in 2018. The IPG's Impact Factor has been increasing over the past few years, and in 2018, it was the highest it has been during the past 5 years. An examination of the previous data shows that the number of cites to recent items published in the IPG have increased by about $10 \%$, while the number of published items has remained steady. This has resulted in a $10 \%$ increase in the Impact Factor from 2017 to 2018. Of course, there is room for further increase in the Impact Factor in the years ahead. Table 4 lists the 20 most cited papers that contributed to the latest available (2018) Impact Factor of the IPG. It may be noted that the IPG publishes more papers than any other journal in geriatric psychiatry. By lowering the rate of acceptance of articles, the quality of the remaining selected papers published in the IPG would improve further, leading to more citations of those papers and a higher Impact Factor.

From a broader community perspective, the usefulness of a medical journal like the IPG can also be 
Table 3. The 20 most popular 2019 articles in terms of usage

Dyer SM, Harrison SL, Laver K, et al. An overview of systematic reviews of pharmacological and non-pharmacological interventions for the treatment of behavioral and psychological symptoms of dementia. International Psychogeriatrics. 2018; 30(3):295-309.

Gualano MR, Voglino G, Bert F, et al. The impact of intergenerational programs on children and older adults: a review. International Psychogeriatrics. 2018; 30(4):451-468.

Lee EE, Depp C, Palmer BW, et al. High prevalence and adverse health effects of loneliness in community-dwelling adults across the lifespan: role of wisdom as a protective factor. International Psychogeriatrics. 2019; 31(10):1447-1462.

Kales HC, Lyketsos CG, Miller EM, et al. Management of behavioral and psychological symptoms in people with Alzheimer's disease: an international Delphi consensus. International Psychogeriatrics. 2019; 31(1):83-90.

Alsawy S, Mansell W, McEvoy P, et al. What is good communication for people living with dementia? A mixed-methods systematic review. International Psychogeriatrics. 2017; 29(11):1785-1800.

Park K, Lee S, Yang J, et al. A systematic review and meta-analysis on the effect of reminiscence therapy for people with dementia. International Psychogeriatrics. Online 2019: 1-17.

Cohen-Mansfield J, Hazan, H, Lerman Y, et al. Correlates and predictors of loneliness in older-adults: a review of quantitative results informed by qualitative insights. International Psychogeriatrics. 2016; 28(4): 557-576.

Thornley J, Hirjee H, Vasudev A, et al. Music therapy in patients with dementia and behavioral disturbance on an inpatient psychiatry unit: results from a pilot randomized controlled study. International Psychogeriatrics. 2016; 28(5):869-871.

Ardelt M, Ferrari M. Effects of wisdom and religiosity on subjective well-being in old age and young adulthood: exploring the pathways through mastery and purpose in life. International Psychogeriatrics. 2019; 31(4):477-489.

Farhang M, Miranda-Castillo C, Rubio M, et al. Impact of mind-body interventions in older adults with mild cognitive impairment: a systematic review. International Psychogeriatrics. 2019; 31(5): 643-666.

Elfrink TR, Zuidema SU, Kunz M, et al. Life story books for people with dementia: a systematic review. International Psychogeriatrics. 2018; 30(12):1797-1811.

Dickinson C, Dow J, Gibson G, et al. Psychosocial intervention for carers of people with dementia: what components are most effective and when? A systematic review of systematic reviews. International Psychogeriatrics. 2017; 29(1):31-43.

Pinto TCC, Machado L, Bulgacov TM, et al. Is the Montreal Cognitive Assessment (MoCA) screening superior to the Mini-Mental State Examination (MMSE) in the detection of mild cognitive impairment (MCI) and Alzheimer's Disease (AD) in the elderly? International Psychogeriatrics. 2019; 31(4):491-504.

Wang G, Albayrak A, van der Cammen TJM, et al. A systematic review of non-pharmacological interventions for BPSD in nursing home residents with dementia: from a perspective of ergonomics. International Psychogeriatrics. 2019; 31(8):1137-1149.

Toot S, Swinson T, Devine M, et al. Causes of nursing home placement for older people with dementia: a systematic review and meta-analysis. International Psychogeriatrics. 2017; 29(2):195-208.

Windle G, Joling KJ, Howson-Griffiths T, et al. The impact of a visual arts program on quality of life, communication, and well-being of people living with dementia: a mixed-methods longitudinal investigation. International Psychogeriatrics. 2018; 30(3):409-423.

Okolie C, 1 Dennis M, Simon-Thomas E, et al. A systematic review of interventions to prevent suicidal behaviors and reduce suicidal ideation in older people. International Psychogeriatrics. 2017; 29(11):1801-1824.

Feast A, Moniz-Cook E, Stoner C, et al. A systematic review of the relationship between behavioral and psychological symptoms (BPSD) and caregiver well-being. International Psychogeriatrics. 2016; 28(11):1761-1774.

Choi NG, DiNitto DM, Marti CN, et al. Association of adverse childhood experiences with lifetime mental and substance use disorders among men and women aged 50 + years. International Psychogeriatrics. 2017; 29(3):59-372.

Wang RH, Sudhama A, Begum M, et al. Robots to assist daily activities: views of older adults with Alzheimer's disease and their caregivers. International Psychogeriatrics. 2017; 29(1):67-79.

assessed by examining the number of times it is cited in the general media (major newspapers, television, and radio) as well as social media including Facebook and Twitter. Many journals use Altmetrics to measure this type of impact of their papers, beyond citations in research journals. Altmetrics tracks the sharing and discussion around research papers through social media sites, newspapers, government policy documents, and other sources. It then uses this information to calculate a score for applicable articles. The Altmetric score is a more instant measure of a paper's impact on the community than say a research citation count. Several papers published last year in the IPG became internationally known through their coverage in various media outlets. Table 5 lists the top 10 papers published in the IPG during all the years, which received the highest Altmetric scores.

Not surprisingly, several papers meet not just one but two of the three criteria for impact mentioned above: usage statistics, Impact Factor, and Altmetric score. For example, two papers on loneliness in the 
Cohen-Mansfield J, Hazan H, Lerman J, et al. Correlates and predictors of loneliness in older-adults: a review of quantitative results informed by qualitative insights. International Psychogeriatrics. 2016; 28(4): 557-576.

Toot S, Swinson T, Devine M, et al. Causes of nursing home placement for older people with dementia: a systematic review and meta-analysis. International Psychogeriatrics. 2017; 29(2):195-208.

Booker A, Jacob LEC, Rapp M, et al. Risk factors for dementia diagnosis in German primary care practices. International Psychogeriatrics. 2016; 28(7):1059-1065.

Yates LA, Ziser S, Spector A, et al. Cognitive leisure activities and future risk of cognitive impairment and dementia: systematic review and meta-analysis. International Psychogeriatrics. 2016; 28(11): 1791-1806.

Burke SL, Maramaldi P, Cadet T, et al. Associations between depression, sleep disturbance, and apolipoprotein E in the development of Alzheimer's disease: dementia. International Psychogeriatrics. 2016; 28(9):1409-1424.

Choi NG, DiNitto DM, Marti CN, et al. Association of adverse childhood experiences with lifetime mental and substance use disorders among men and women aged 50 + years. International Psychogeriatrics. 2017; 29(3):359-372.

Dickinson C, Dow J, Gibson G, et al. Psychosocial intervention for carers of people with dementia: What components are most effective and when? A systematic review of systematic reviews. International Psychogeriatrics. 2017; 29(1):31-43.

Amieva H, Robert PH, G A, et al. Group and individual cognitive therapies in Alzheimer's disease: the ETNA3 randomized trial. International Psychogeriatrics. 2016; 28(5):707-717.

Pozzebon M, Douglas J, Ames D, et al. Spouses' experience of living with a partner diagnosed with a dementia: a synthesis of the qualitative research. International Psychogeriatrics. 2016; 28(4): 537-556.

Vaingankar JA, Chong SA, Abdin E, et al. Care participation and burden among informal caregivers of older adults with care needs and associations with dementia. International Psychogeriatrics. 2016; 28(2): 221-231.

Wang RH, Sudhama A, Begum M, et al. Robots to assist daily activities: views of older adults with Alzheimer's disease and their caregivers. International Psychogeriatrics. 2017; 29(1):67-79.

Jøranson N, Pedersen I, Rokstad AMM, Aamodt G, et al. Group activity with Paro in nursing homes: systematic investigation of behaviors in participants. International Psychogeriatrics. 2016; 28(8): 1345-1354.

Ihle A, Oris M, Fagot D, et al. The association of educational attainment, cognitive level of job, and leisure activities during the course of adulthood with cognitive performance in old age: the role of openness to experience. International Psychogeriatrics. 2016; 28(5):733-740.

van Schoor NM, Comijis HC, Llewellyn, DJ, et al. Cross-sectional and longitudinal associations between serum 25-hydroxyvitamin D and cognitive functioning. International Psychogeriatrics. 2016; 28(5):759-768.

Ryu SY, Lim EY, Na S, et al. Hippocampal and entorhinal structures in subjective memory impairment: a combined MRI volumetric and DTI study. International Psychogeriatrics. 2017; 29(5):785-792

Feast A, Moniz-Cook E, Stoner C, et al. A systematic review of the relationship between behavioral and psychological symptoms (BPSD) and caregiver well-being. International Psychogeriatrics. 2016; 28(11):1761-1774.

Van der Spek K, Gerritsen DL, Smallbrugge M, et al. Only 10\% of the psychotropic drug use for neuropsychiatric symptoms in patients with dementia is fully appropriate. The PROPER I-study. International Psychogeriatrics. 2016; 28(10):1589-1595.

Kamiya Y, Timonen V, Kenny RA, et al. The impact of childhood sexual abuse on the mental and physical health, and healthcare utilization of older adults. International Psychogeriatrics. 2016; 28(3):415-422.

Rye SY, Lee SB, Kin TW, et al. Subjective memory complaints, depressive symptoms and instrumental activities of daily living in mild cognitive impairment. International Psychogeriatrics. 2016; 28(3):487-494.

Nirmalasar O, Mamo SK, Nieman CL, et al. Age-related hearing loss in older adults with cognitive impairment. International Psychogeriatrics. 2017; 29(11):1771-1784.

community which had high usage also had high number of cites in scientific journals (Cohen-Mansfield et al., 2016) or high Altmetric score (Lee et al., 2019). A paper on views about robots in people with dementia and their caregivers received high usage and also high number of scientific citations (Wang et al., 2017). Two papers on behavioral and psychological symptoms in dementia that had high usage scores were either cited frequently by researchers (Feast et al., 2016) or by the media (Kales et al., 2019). Another paper (Choi et al., 2017) associating adverse childhood experiences with later life mental and substance use disorders had high usage as well as high number of cites in scientific journals. It should be added that typically, the number of cites in scientific journals to a published paper tends to increase over time, whereas the usage statistics and Altmetric score may not.

\section{Plans for the coming years}

The IPG Editorial team, in consultation with the Board of Directors of the IPA as well as other stakeholders, will continue to engage in a dialogue to help the journal progress further. We welcome input from 
Table 5. Top 10 papers with the highest altmetric scores, all years

Scelzo A, Di Somma S, Antonini P, et al. Mixed-methods quantitative-qualitative study of 29 nonagenarians and centenarians in rural Southern Italy: focus on positive psychological traits. International Psychogeriatrics. 2018; 30(1):31-38.

Lee EE, Depp C, Palmer BW, et al. High prevalence and adverse health effects of loneliness in community-dwelling adults across the lifespan: role of wisdom as a protective factor. International Psychogeriatrics. 2019; 31(10):1447-1462.

Burke SL, Maramaldi P, Cadet T, et al. Associations between depression, sleep disturbance, and apolipoprotein E in the development of Alzheimer's disease: dementia. International Psychogeriatrics. 2016; 28(9):1409-1424.

Kales HC, Lyketsos CG, Miller EM, et al. Management of behavioral and psychological symptoms in people with Alzheimer's disease: an international Delphi consensus. International Psychogeriatrics. 2019; 31(1):83-90.

Giebel CM, Sutcliffe C, Renom-Guiteras A, et al. Depressive symptomatology in severe dementia in a European sample: prevalence, associated factors and prescription rate of antidepressants. International Psychogeriatrics. 2015; 27(4):657-667.

Toot S, Swinson T, Devine M, et al. Causes of nursing home placement for older people with dementia: a systematic review and meta-analysis. International Psychogeriatrics. 2017; 29(2):195-208.

Small GW, Siddarth P, Ercolo LM, et al. Healthy behavior and memory self-reports in young, middle-aged, and older adults. International Psychogeriatrics. 2013; 25(6):991.

Almeida OP, Ford AH, Flicker L. Systematic review and meta-analysis of randomized placebo-controlled trials of folate and vitamin B12 for depression. International Psychogeriatrics. 2015; 27(5):727-737.

Hamina A, Lavikainen P, Tanskanen A, et al. Impact of opioid initiation on antipsychotic and benzodiazepine and related drug use among persons with Alzheimer's disease. International Psychogeriatrics. 2018; 30(7):947-956.

Quinn C, Toms G, Jones C, et al. A pilot randomized controlled trial of a self-management group intervention for people with early-stage dementia (The SMART study). International Psychogeriatrics. 2016; 28(5):787-800.

the membership of the IPA and the overall readership of the IPG. Similarly, authors' and reviewers' comments are also very helpful.

The journal's website is undergoing improvements and updates. Given the rapidly spreading general trend, supplemental digital content will allow the IPG to publish content online that otherwise could not be published in print. To ensure transparency regarding ethical issues and avoidance of conflicts of interest, we will publish an annual listing of all potential conflicts of interest and/or funding disclosures from members of the Editorial Board.

Our goal is to ensure that the IPG becomes and remains the leading forum for publication of cuttingedge science in aging-related mental and behavioral health and neuroscience. At the same time, the published papers must be useful to clinicians and trainees. We will also strive to maintain the international nature of the IPG, while raising the quality of the science published. I have no doubt that the best days and years for the IPG lie ahead of us.

\section{Acknowledgements}

I am personally thankful to a number of colleagues for their help with this article. I particularly want to acknowledge Jessica Bradley, the Publishing Editor of the International Psychogeriatrics, and Elaine Halls, the IPG Editorial Officer Manager, for their incredible help with the tables and figures included in this paper.
Dilip V. JESTE ${ }^{1,2}$

${ }^{1}$ Departments of Psychiatry and Neurosciences, University of California San Diego, La Jolla, CA, USA ${ }^{2}$ Sam and Rose Stein Institute for Research on Aging, University of California San Diego, La Jolla, CA, USA

\section{References}

Choi, N. G., DiNitto, D. M., Marti, C. N. and Choi, B. Y. (2017). Association of adverse childhood experiences with lifetime mental and substance use disorders among men and women aged $50+$ years. International Psychogeriatrics, 29, 59-372. doi: 10.1017/S1041610216001800.

Cohen, G., Bergener, M. B., Kazuo, H. and Finkel, S. I. (1989). Editorial. International psychogeriatric association mission and vision. International Psychogeriatrics, 1, 3-4. doi: 10.1017/S1041610289000013.

Cohen-Mansfield, J., Hazan, H., Lerman, Y. and Shalom, V. (2016). Correlates and predictors of loneliness in older-adults: a review of quantitative results informed by qualitative insights. International Psychogeriatrics, 28, 557-576. doi: 10.1017/S1041610215001532.

Feast, A., Moniz-Cook, E., Stoner, C., Charlesworth, G. and Orrell, M. (2016). A systematic review of the relationship between behavioral and psychological symptoms (BPSD) and caregiver well-being. International Psychogeriatrics, 28, 1761-1774. doi: 10.1017/ S1041610216000922.

Jeste, D. V. (2018a). International psychogeriatrics turns a new page: new editor begins his term. International Psychogeriatrics, 30, 1-3. doi: 10.1017/ S1041610217002915. 
Jeste, D. V. (2018b). Positive psychiatry comes of age. International Psychogeriatrics, 30, 1735-1738. doi: 10.1017/ S1041610218002211.

Kales, H. C., Lyketsos, C. G., Miller, E. M. and Ballard, C. (2019). Management of behavioral and psychological symptoms in people with Alzheimer's disease: an international Delphi consensus.

International Psychogeriatrics, 31, 83-90. doi: $10.1017 /$ S1041610218000534.

Lautenschlager, N. T. (2014). International Psychogeriatrics and the International Psychogeriatric Association: a successful marriage turns silver.
International Psychogeriatrics, 26, 1-2. doi: 10.1017/ S1041610213001968.

Lee, E. E. et al. (2019). High prevalence and adverse health effects of loneliness in community-dwelling adults across the lifespan: role of wisdom as a protective factor. International Psychogeriatrics, 31, 1447-1462. doi: 10.1017/ S1041610218002120.

Wang, R. H., Sudhama, A., Begum, M., Huq R. and Mihailidis A. (2017). Robots to assist daily activities: views of older adults with Alzheimer's disease and their caregivers. International Psychogeriatrics, 29, 67-79. doi: 10.1017/S1041610216001435. 